\title{
Sequence Determination of rRNA Genes of Pathogenic Vibrio Species and Whole-Cell Identification of Vibrio vulnificus with rRNA-Targeted Oligonucleotide Probes
}

\author{
R. AZNAR,* W. LUDWIG, R. I. AMANN, AND K. H. SCHLEIFER \\ Lehrstuhl für Mikrobiologie, Technische Universität München, D-80290 Munich 2, Germany
}

\begin{abstract}
A comparative analysis of seven new 16S rRNA gene sequences of pathogenic Vibrio species with previously published vibrio sequences confirmed that Vibrio vulnificus represents a group that is not closely related to the core organisms of the genus Vibrio. In addition, we found that $V$. vulnificus, Listonella (Vibrio) anguillarum and Vibrio diazotrophicus branch off separately from the core group. A comparison of the 16S rRNA gene sequences of $V$. vulnificus strains belonging to biotypes 1 and 2 revealed that the sequences of all but four biotype 1 strains were identical to each other but slightly different ( 17 bases) from the sequences of the rest of the $V$. vulnificus strains investigated. In addition, the sequences of variable regions of the 23S rRNA genes of Vibrio fluvialis, Vibrio furnissii, Vibrio harveyi, Vibrio cholerae, and $V$. vulnificus $C 7184$ and TW1 were determined, aligned, and compared with all available bacterial $23 S$ rRNA sequences in order to search for specific target sites. As a result, four oligonucleotide probes specific for $V$. vulnificus were synthesized, and the specificities of these probes were evaluated by dot blot hybridization to membrane-bound RNAs from $21 \mathrm{~V}$. vulnificus strains, 13 strains belonging to other Vibrio species, 61 strains belonging to species that are members of the alpha, beta, and gamma subclasses of the Proteobacteria, and 3 eucaryotic microorganisms. Two probes hybridized with all of the $V$. vulnificus strains tested, and the other two probes distinguished $V$. vulnificus biotype 1 strains from all other organisms. In situ identification of $V$. vulnificus by using tetramethylrhodamine- or fluorescein-labelled oligonucleotides is now possible.
\end{abstract}

The first description of the taxon that is designated Vibrio vulnificus was published by Baumann et al. (5); in a taxonomic study of marine bacteria, these authors reported that a group designated $\mathrm{C} 2$ could be clearly distinguished phenotypically. Subsequently, in 1976 Reichelt et al. (25) performed DNADNA hybridization studies whose results showed that this taxon was a separate species, which was then named Beneckea vulnifica. The present name, $V$. vulnificus, was revived by Farmer in 1980 (13) to describe a group of lactose-positive Vibrio strains which were phenotypically and genetically distinct from other Vibrio species (31). These organisms are common inhabitants of estuarine and marine waters, and they can be isolated under a wide range of salinity and temperature conditions from oysters, clams, mussels, and fish, as well as from sediment and plankton. Recent studies of the incidence of $V$. vulnificus in the United States have shown that it is present along the Gulf Coast, the Atlantic Coast, and the West Coast, and several cases of shellfish-associated $V$. vulnificus infections have been reported (23). The disease syndromes caused by $V$. vulnificus include septicemia and gastroenteritis following ingestion of shellfish and wound infections derived from contact with shellfish or the marine environment. In immunodepressed individuals the infections can be fatal. Stelma et al. (29) found no significant differences in virulence between clinical and environmental isolates. The species $V$. vulnificus also includes strains pathogenic for eels which have been responsible for severe recurrent epizootic outbreaks in cultured eels and are referred to as biotype 2 strains $(7,30)$.

Since $V$. vulnificus has become a public health problem, as well as a major obstacle in aquaculture, a rapid and effective detection method is needed in order to monitor its presence in

* Corresponding author. Present address: Departamento de Microbiología, Universitat de Valencia, Av. Dr. Moliner, 50, E-46100 Burjassot, Valencia, Spain. the environment, especially since biotype 2 strains have been isolated only from diseased eels.

Nucleic acid probes can be used for rapid and specific identification of microorganisms (28). In 1987, Morris et al. (21) described a DNA probe for the cytotoxin-hemolysin gene of $V$. vulnificus. Later, oligonucleotide primers directed to the gene sequence were used in a PCR in attempts to identify $V$. vulnificus in artificially contaminated oysters (16) and to detect culturable and nonculturable $V$. vulnificus cells (8). However, this approach was not successful, and the authors discussed the possibility that the cytotoxin-hemolysin gene was lost. Such losses do not occur when DNA probes directed against rRNAs are used. rRNA molecules are essential constituents of all living organisms and are present in growing cells in very high copy numbers. rRNA-targeted probes are excellent tools for rapid in situ identification of whole cells $(2,11)$ and for colony hybridization $(6,15)$.

The aims of this study were to investigate the phylogenetic relationships of some pathogenic Vibrio species and to design rRNA-targeted oligonucleotide probes specific for $V$. vulnificus.

\section{MATERIALS AND METHODS}

Bacterial strains and growth conditions. Twenty-one $V$. vulnificus biotype 1 and 2 strains were used in this study. The $V$. vulnificus biotype 1 strains included the type strain of the species, ATCC 27562, clinical isolates C7184, L-180, Vvl1, UHM1, and 374, and four wild strains recovered either from gills of European eels (Anguilla anguilla) or from the tank water of an eel farm. The $V$. vulnificus biotype 2 strains included reference strains NCIMB 2136, NCIMB 2137, NCIMB 2138, and ATCC 33149 and six isolates recovered from internal organs of European eels (A. anguilla). All wild strains were isolated from an eel farm during different epizootic outbreaks of vibriosis in Spain $(3,7)$. We also studied 
the type strains of Vibrio harveyi, Vibrio furnissii, Vibrio fluvialis, and Vibrio cholerae and one $V$. cholerae non-O1 environmental isolate. In addition, 77 strains (13 strains belonging to other Vibrio species, 61 strains belonging to species that are members of the alpha, beta, and gamma subclasses of the Proteobacteria, and 3 eucaryotic microorganisms) were used to test the specificity of oligonucleotide probes. All of these strains and their sources are listed in Table 1.

The Vibrio strains were grown in brain heart infusion medium (Difco) supplemented with $0.5 \%$ (wt/vol) $\mathrm{NaCl}$ and $1.5 \%$ agar (for solid medium) for $24 \mathrm{~h}$. The clinical strains were incubated at $37^{\circ} \mathrm{C}$, and the environmental isolates were incubated at $25^{\circ} \mathrm{C}$. For in situ hybridization experiments, in order to maximize the cellular rRNA content, cells were harvested at the mid-logarithmic phase by centrifugation in an Eppendorf Microfuge at $5000 \times g$ for $5 \mathrm{~min}$. The pelleted cells were washed once and then resuspended in phosphate-buffered saline (PBS) (130 mM sodium chloride, $10 \mathrm{mM}$ sodium phosphate; $\mathrm{pH} 7.2)$.

Cell fixation. Cells were fixed in a paraformaldehyde solution and were stored in a 1:1 mixture of PBS and 96\% ethanol at $-20^{\circ} \mathrm{C}$ as described previously (1). The fixed cells were spotted onto gelatin-coated slides, dried at $37^{\circ} \mathrm{C}$ for $2 \mathrm{~h}$, and dehydrated in 50, 80, and $96 \%$ (vol/vol) ethanol ( $3 \mathrm{~min}$ each).

PCR and sequence determination. In vitro amplification and direct sequencing of $16 \mathrm{~S}$ and $23 \mathrm{~S}$ rRNA genes were performed as described previously (19).

Purification of nucleic acids. Genomic DNA was extracted by the guanidium thiocyanate method of Pitcher et al. (24) and was further purified by RNase and proteinase $\mathrm{K}$ treatments as described by Sambrook et al. (27). RNA was isolated as follows. Cells from 2-ml overnight cultures were harvested by centrifugation and suspended in $400 \mu \mathrm{l}$ of $0.01 \mathrm{M}$ Tris- $\mathrm{HCl}-$ 0.001 M EDTA ( $\mathrm{pH} 8.0$ ). A $50-\mu$ l portion of $25 \%$ sodium dodecyl sulfate (SDS) and $450 \mu$ l of a chloroform-phenolisoamyl alcohol $(24: 25: 1)$ mixture were added, and samples were incubated at $60^{\circ} \mathrm{C}$ for $10 \mathrm{~min}$. After centrifugation at $12,000 \times g$, for $10 \mathrm{~min}$, the supernatants were extracted with phenol. The nucleic acids were precipitated by adding 2.5 volumes of ethanol in the presence of $0.3 \mathrm{M}$ sodium acetate.

Immobilization of RNA onto membranes. RNA samples (1.5 $\mu \mathrm{g}$ ) were denatured at $60^{\circ} \mathrm{C}$ for $10 \mathrm{~min}$ in $100 \mu \mathrm{l}$ of a buffer containing $50 \%$ formamide, $4 \%$ formaldehyde, $0.02 \mathrm{M} \mathrm{3}-(\mathrm{N}-$ morpholino)propanesulfonic acid, $0.005 \mathrm{M}$ sodium acetate, and $0.001 \mathrm{M}$ EDTA. The denatured RNA samples were applied to Qiabrane nylon membranes (Diagen, Düsseldorf, Germany) according to the manufacturer's specifications by using a Minifold dot blot apparatus (Schleicher \& Schuell, Dassel, Germany). The membranes were air dried, and the nucleic acids were immobilized on the membranes by heating the preparations at $80^{\circ} \mathrm{C}$ for $30 \mathrm{~min}$.

Dot blot hybridizations with nonradioactively labelled probes. Hybridizations and hybrid detection by chemiluminescence were carried out by using components of a DNA labelling kit, anti-digoxigenin antibodies, and AMPPD [3-(2'spiroadamantane)-4-methoxy-4-(3"-phosphoryloxy)phenyl-1,2dioxetane] obtained from Boehringer, Mannheim, Germany. Membranes were prehybridized in a solution containing $5 \times$ SSC $(1 \times$ SSC is $0.15 \mathrm{M} \mathrm{NaCl}$ plus $0.015 \mathrm{M}$ sodium citrate, $\mathrm{pH}$ 7.0), 5\% blocking reagent, $0.1 \% \mathrm{~N}$-lauroyl-sarcosine, and $0.02 \%$ SDS for $1 \mathrm{~h}$. The hybridization solution contained $0.9 \mathrm{M}$ $\mathrm{NaCl}, 10 \mathrm{mM}$ Tris- $\mathrm{HCl}$ (pH 7.2), $0.01 \%$ SDS, $0.1 \% \mathrm{~N}$-lauroylsarcosine, 4\% blocking reagent, and $50 \mathrm{ng}$ of digoxigeninlabelled oligonucleotide. The hybridization mixtures were incubated overnight at $46^{\circ} \mathrm{C}$. Subsequently, the membranes were washed twice in a solution containing $0.9 \mathrm{M} \mathrm{NaCl}, 10 \mathrm{mM}$
Tris- $\mathrm{HCl}, 0.01 \%$ SDS, and $0.1 \% N$-lauroyl-sarcosine at the hybridization temperature. Hybridization was detected as described by the manufacturer.

Colony hybridization. Vibrios were grown on Qiabrane membranes (Diagen) layered on brain heart infusion agar under the conditions described above. To lyse the cells and to denature the DNA, the membranes were incubated for $10 \mathrm{~min}$ on filter paper saturated with a high-salt denaturation solution containing $0.5 \mathrm{M} \mathrm{NaOH}$ and $1.5 \mathrm{M} \mathrm{NaCl}$ with the colony side up. Then the membranes were placed briefly on dry filter paper to remove the excess fluid. The preparations were neutralized by placing the membranes on filter paper saturated with neutralizing solution containing $0.5 \mathrm{M}$ Tris- $\mathrm{HCl}(\mathrm{pH} 7.4)$ and $1.5 \mathrm{M} \mathrm{NaCl}$ for $5 \mathrm{~min}$, and then the membranes were placed on filter paper saturated with $2 \times \mathrm{SSC}$ for $5 \mathrm{~min}$. The bacterial residues were removed by washing the membranes in $2 \times \mathrm{SSC}$. Then, the residues were air dried, and their DNAs were immobilized by incubating the preparations at $80^{\circ} \mathrm{C}$ for $30 \mathrm{~min}$. Hybridization experiments were performed as described above.

In situ hybridization. The complete $23 \mathrm{~S}$ rRNA sequence of $V$. vulnificus and partial sequences of the 23S rRNA genes of $V$. vulnificus biotype 1 strains TW1 and C7184, V. fluvialis NCTC $11327^{\mathrm{T}}$ ( $\mathrm{T}=$ type strain), $V$. furnissii ATCC $35016^{\mathrm{T}}$, $V$. cholerae CECT $514^{\mathrm{T}}$, and $V$. harveyi NCIMB $1280^{\mathrm{T}}$ were aligned and compared with all available bacterial $23 \mathrm{~S}$ rRNA sequences in order to search for specific target sites. Oligonucleotides complementary to selected regions were synthesized with a C6-TFA aminoilink [6-(trifluoroacetyl-amino) - hexyl-(2 - cyanoethyl)( $N, N$-diisopropyl)-phosphoramidite] (MWG Biotech, Ebersberg, Germany) at the $5^{\prime}$ end. The sequences and target sites used are shown in Table 2. In addition, probe EUB338, a oligonucleotide complementary to a region of $16 \mathrm{~S}$ rRNA conserved in members of the domain Bacteria, was used as a positive control for hybridizations (1). Labelling with tetramethylrhodamine-5-isothiocyanate (TRITC; Molecular Probes, Eugene, Oreg.) or 5(6)-carboxy-fluorescein- $N$-hydroxysuccinimide ester (FLUOS; Boehringer) was performed as described previously (1). An aliquot $(8 \mu \mathrm{l})$ of hybridization solution $(0.9$ $\mathrm{M} \mathrm{NaCl}, 20 \mathrm{mM}$ Tris- $\mathrm{HCl}$ [pH 7.2], 0.01\% SDS, $25 \mathrm{ng}$ of probe) was added to each well of a microscopic slide, and the preparation was incubated for $1.5 \mathrm{~h}$ at $46^{\circ} \mathrm{C}$ in an isotonically equilibrated humidity chamber. The probe was removed from the slide with $2 \mathrm{ml}$ of washing solution $(0.9 \mathrm{M} \mathrm{NaCl}, 20 \mathrm{mM}$ Tris- $\mathrm{HCl}$ [pH 7.2], $0.01 \%$ SDS) and immediately immersed in $50 \mathrm{ml}$ of washing solution at $48^{\circ} \mathrm{C}$ for $20 \mathrm{~min}$. The slides were rinsed briefly with distilled water, air dried, and mounted in Citifluor (Citifluor, Ltd., London, United Kingdom).

Fluorescence was detected with a Zeiss Axioplan microscope (Zeiss, Oberkochen, Germany) fitted for epifluorescence microscopy with a 50-W mercury high-pressure bulb and Zeiss filter sets 09 and 15 . Color micrographs were prepared by using Kodak Ektachrome P1600 color reversal film. The exposure times used were 0.01 to $0.03 \mathrm{~s}$ for phase-contrast micrographs and 10 to $60 \mathrm{~s}$ for epifluorescence micrographs.

Data analysis. The new 16S rRNA primary structures were introduced into an alignment of 1,200 homologous sequences on the basis of primary and higher-order structure similarities. Similarity values and phylogentic distances (17) were calculated and alignment positions were selected on the basis of the degrees of evolutionary conservation by using the SEQDIS program (N. Stuckmann and W. Ludwig, unpublished data). Distance matrix, maximum-parsimony, and maximum-likelihood analyses were performed by using the NEIGHBOR (26) and DNAPARS programs of Felsenstein's PHYLIP package (14) and the fastDNAml program of Olsen et al. (22), respec- 
TABLE 1. Strains used in this study

\begin{tabular}{|c|c|c|c|}
\hline Position $^{a}$ & Taxon & Strain $^{b}$ & Origin \\
\hline A.1 & Rhodobacter capsulata & LMG 2962 & \\
\hline A. 2 & Paracoccus denitrificans & LMG 4218 & \\
\hline A.3 & Pseudomonas diminuta & LMG 2089 & \\
\hline A. 4 & Rhodopseudomonas palustris & DSM 123 & \\
\hline A.5 & Rhizobium meliloti & DSM 30135 & \\
\hline A. 6 & Magnetospirillum gryphiswaldense & DSM 6361 & \\
\hline A.7 & Bradyrhizobium japonicum & DSM 30131 & \\
\hline A. 8 & Agrobacterium tumefaciens & DSM 30205 & \\
\hline A. 9 & Rhodospirillum rubrum & DSM 467 & \\
\hline A. 10 & Azospirillum halopreferens & DSM 3675 & \\
\hline A.11 & Azospirillum brasiliense & DSM 1690 & \\
\hline A.12 & Azospirillum amazonense & DSM 2787 & \\
\hline B.1 & Leucothrix mucor & DSM 2157 & \\
\hline B. 2 & Shewanella putrefaciens & LMG 2268 & \\
\hline B.3 & Acinetobacter calcoaceticus & LMG 1046 & \\
\hline B. 4 & Pseudomonas cepacia & LMG 1222 & \\
\hline B.5 & Chromobacter violaceum & LMG 1267 & \\
\hline B.6 & Alcaligenes faecalis & LMG 1229 & \\
\hline B.7 & Alcaligenes eutrophus & LMG 1199 & \\
\hline B. 8 & Aquaspirillum metamorphum & LMG 4338 & \\
\hline B.9 & Sphaerotilus natans & LMG 7172 & \\
\hline B.10 & Comamonas testosteroni & DSM 50244 & \\
\hline B.11 & Zoogloea ramigera & LMG 4432 & \\
\hline B.12 & Thiobacillus acidophilus & DSM 700 & \\
\hline C.1 & Pseudomonas pseudoalcaligenes & LMG 1225 & \\
\hline C.3 & Pseudomonas alcaligenes & LMG 1224 & \\
\hline C. 5 & Serratia marcescens & DSM 30121 & \\
\hline C.6 & Proteus vulgaris & DSM 30118 & \\
\hline C.7 & Erwinia carotovora & DSM 30168 & \\
\hline C. 8 & Enterobacter cloacae & DSM 30054 & \\
\hline C.9 & Enterobacter aerogenes & DSM 30053 & \\
\hline C. 10 & Escherichia coli & DSM 30083 & \\
\hline C.11 & Listonella (Vibrio) anguillarum & NCIMB 2129 & \\
\hline C.12 & Aeromonas hydrophila & LMG 2844 & \\
\hline D.1 & Pseudomonas putida & LMG 2257 & \\
\hline D.2 & Myxococcus virescens & DSM 2260 & \\
\hline D. 3 & Myxococcus fulvus & DSM 434 & \\
\hline D.4 & Cytophaga johnsonae & LMG 1341 & \\
\hline D.5 & Flavobacterium ferrugineum & DSM 30193 & \\
\hline D.6 & Propionibacterium freudenreichii & DSM 4902 & \\
\hline D.7 & Pimelobacter simplex & DSM 20130 & \\
\hline D. 8 & Brevibacterium ketoglutamicum & DSM 20165 & \\
\hline D.9 & Brevibacterium linens & DSM 20425 & \\
\hline D.10 & Rhodococcus rhodochrous & LMG 5365 & \\
\hline D.11 & Micrococcus luteus & DSM 20030 & \\
\hline D.12 & Corynebacterium glutamicum & DSM 20300 & \\
\hline E.1 & Streptococcus salivarius & DSM 20560 & \\
\hline E.2 & Staphylococcus aureus & DSM 20231 & \\
\hline E.3 & Lactococcus lactis subsp. cremoris & DSM 20069 & \\
\hline E.4 & Lactococcus lactis subsp. lactis & DSM 20481 & \\
\hline E.5 & Lactobacillus casei & DSM 20011 & \\
\hline E.6 & Enterococcus faecalis & DSM 20478 & \\
\hline E.7 & Enterococcus faecium & DSM 20477 & \\
\hline E. 8 & Pectinatus frisingensis & ATCC 33332 & \\
\hline E.9 & Clostridium stercorarium & NCIMB $11754^{\mathrm{T}}$ & \\
\hline E.10 & Clostridium acetobutylicum & DSM 792 & \\
\hline E.11 & Bacillus subtilis & DSM 10 & \\
\hline E.12 & Bacillus cereus & DSM 31 & \\
\hline F.8 & Aquaspirillum (Magnetospirillum) magnetotacticum & DSM 3856 & \\
\hline F.9 & Saccharomyces cerevisiae & DSM 70449 & \\
\hline F.10 & Saccharomyces carlsbergiensis (formerly Saccharomyces uvarum) & $66^{c}$ & \\
\hline F.11 & Hansenula anomala & DSM 70255 & \\
\hline F.12 & Staphylococcus carnosus & DSM 20501 & \\
\hline G.2 & Vibrio tubiashii & NCIMB $1340^{\mathrm{T}}$ & \\
\hline G.3 & Vibrio carchariae & NCIMB $12705^{\mathrm{T}}$ & \\
\hline G.4 & Vibrio damsela & CECT $626^{\mathrm{T}}$ & \\
\hline G.5 & Listonella (Vibrio) anguillarum & NCIMB $6^{\mathrm{T}}$ & \\
\hline G.7 & Vibrio vulnificus biotype 2 & $\mathrm{E} 39^{d}$ & European eel \\
\hline
\end{tabular}


TABLE 1-Continued

\begin{tabular}{|c|c|c|c|}
\hline Position $^{a}$ & Taxon & Strain $^{b}$ & Origin \\
\hline & & $\mathrm{E} 22^{d}$ & European eel \\
\hline & & $\mathrm{E} 58^{d}$ & European eel \\
\hline & & $\mathrm{E} 64^{d}$ & European eel \\
\hline & & $\mathrm{E} 86^{d}$ & European eel \\
\hline & & $\mathrm{E} 105^{d}$ & European eel \\
\hline G.8 & & ATCC 33149 & Japanese eel \\
\hline \multirow[t]{3}{*}{ G.9 } & & NCIMB 2138 & Japanese eel \\
\hline & & NCIMB 2137 & Japanese eel \\
\hline & & NCIMB 2136 & Japanese eel \\
\hline \multirow[t]{5}{*}{ G.10 } & Vibrio vulnificus biotype 1 & $\mathrm{TW} 1^{d}$ & Tank water \\
\hline & & $\mathrm{E} 63^{d}$ & European eel \\
\hline & & $\mathrm{E} 114^{d}$ & European eel \\
\hline & & $\mathrm{E} 335^{d}$ & Glass eels \\
\hline & & $\mathrm{E} 647^{d}$ & European eel \\
\hline G.11 & & $\mathrm{C} 7184^{e}$ & Human blood \\
\hline \multirow[t]{5}{*}{ G.12 } & & ATCC $27562^{\mathrm{T}}$ & Human wound infection \\
\hline & & $\mathrm{L}-180^{\circ}$ & Septicemia case \\
\hline & & $\mathrm{VvL1}^{e}$ & Fatal wound infection \\
\hline & & $374^{e}$ & Septicemia case \\
\hline & & $\mathrm{UMH} 1^{e}$ & Fatal wound infection \\
\hline H.1 & Shewanella putrefaciens & CECT $331^{\mathrm{T}}$ & \\
\hline H.2 & Aeromonas salminicida subsp. salmonicida & CECT 894 & \\
\hline H.4 & Vibrio mimicus & NCTC $11435^{\mathrm{T}}$ & \\
\hline \multirow[t]{2}{*}{ H.5 } & Vibrio cholerae $\mathrm{O} 1$ & CECT $514^{\mathrm{T}}$ & \\
\hline & Vibrio cholerae non-O1 & $137^{f}$ & Freshwater \\
\hline H.6 & Vibrio parahaemolyticus & CECT $511^{\mathrm{T}}$ & \\
\hline H.7 & Vibrio pelagius & ATCC $25916^{\mathrm{T}}$ & \\
\hline H.8 & Vibrio alginolyticus & NCIMB $1903^{\mathrm{T}}$ & \\
\hline H.9 & Vibrio cincinatiensis & NCTC $12012^{\mathrm{T}}$ & \\
\hline H.10 & Vibrio furnissii & ATCC $35016^{\mathrm{T}}$ & \\
\hline H.11 & Vibrio fluvialis & NCTC $11327^{\mathrm{T}}$ & \\
\hline H.12 & Vibrio harveyi & NCIMB $1280^{\mathrm{T}}$ & \\
\hline
\end{tabular}

${ }^{a}$ Position on the membrane used for the dot blot hybridization experiment (see Fig. 2).

${ }^{b}$ Abbreviations: ATCC, American Type Culture Collection, Rockville, Md; CECT, Collección Española de Cultivos Typo, Valencia, Spain; DSM, Deutsche Sammlung von Mikroorganismen and Zellkulturen, Braunschweig, Germany; LMG, Belgian Coordinated Collections of Microorganisms, Laboratorium voor Microbiologie, Universiteit Gent, Ghent, Belgium; NCIMB, National Collection of Industrial and Marine Bacteria, Torry Research Station, Aberdeen, Scotland; NCTC, National Collection of Type Cultures, London, United Kingdom.

${ }^{c}$ Obtained from the Institut für Brausereitechnologie und Mikrobiologie, Technische Universität, Munich, Germany.

${ }^{d}$ Environmental isolate kindly supplied by E. G. Biosca and M. Oritigosa, University of Valencia, Burjasot, Valencia, Spain.

${ }^{e}$ Clinical isolate kindly supplied by J. D. Oliver, University of North Carolina, Charlotte.

${ }^{f}$ Environmental isolate kindly supplied by C. Amaro, University of Valencia, Burjasot, Valencia, Spain.

tively. The topologies of the trees were evaluated by using different treeing methods and various data sets that differed with respect to selection of reference sequences and alignment positions.

Nucleotide sequence accession numbers. The 16S rRNA

TABLE 2. Sequences of the oligonucleotide probes, specificities, and hybridization conditions ${ }^{a}$

\begin{tabular}{|c|c|c|c|c|}
\hline \multirow{2}{*}{ Probe } & \multirow{2}{*}{ Sequence } & \multirow{2}{*}{$\begin{array}{c}\text { Specificity } \\
\text { (16S rRNA } \\
\text { type) }\end{array}$} & \multicolumn{2}{|c|}{$\begin{array}{l}\text { Hybridization } \\
\text { conditions }\end{array}$} \\
\hline & & & $\begin{array}{l}\text { Temp } \\
\left({ }^{\circ} \mathrm{C}\right)\end{array}$ & $\begin{array}{l}\text { Formamide } \\
\text { concn }(\%)\end{array}$ \\
\hline Vvu1 & 5'-CATAGAACATTGCCGCAG-3' & A & 46 & 40 \\
\hline Vvu2 & 5'-ACTCAATGATACTGGCT'TA-3' & $\mathrm{A}, \mathrm{B}$ & 46 & 0 \\
\hline Vvu3 & $5^{\prime}$-ACCGTTCGTCTAACACAT-3' & A, B & 46 & 25 \\
\hline Vvu4 & $5^{\prime}$-'TCAAAGAACATTGCCGCA-3' & B & 46 & 40 \\
\hline
\end{tabular}

${ }^{a}$ All probes were 23S rRNA targeted and were specific for $V$. vulnificus. They were able to separate biotype 1 strains into the following two groups corresponding to two different $16 \mathrm{~S}$ rRNA sequences: type A, $16 \mathrm{~S}$ rRNAs corresponding to V. vulnificus type strain ATCC 27562 (biotype 1) and $V$. vulnificus NCIMB 2138 (biotype 2) rRNAs; type B, rRNAs corresponding to $V$. vulnificus biotype 1 strains C7184 and TW1. sequences determined in this study have been deposited in the EMBL data base under accession numbers X76333, X76334, X76335, X76336, and X76337.

\section{RESULTS}

Phylogenetic relatedness of $\boldsymbol{V}$. vulnificus biotypes and other Vibrio species. A comparison of the complete sequences of PCR-amplified 23S and 16S rRNA genes of $V$. vulnificus biotype 1 type strain ATCC 27562 and biotype 2 reference strain NCIMB 2138 revealed no differences between the sequences of the two strains. The partial 23S rRNA and complete 16S rRNA sequences of $V$. vulnificus biotype 1 strains TW1 and C7184 were identical (rRNA type B), but were slightly different ( 2 of 600 bases in the 23S rRNA and 17 bases in the complete 16S rRNA sequence) from the corresponding sequences (rRNA type A) of the two reference strains mentioned above. The complete sequences of the $16 \mathrm{~S}$ rRNA genes of the $V$. vulnificus strains, $V$. fluvialis NCTC $11327^{\mathrm{T}}, V$. furnissii ATCC $35016^{\mathrm{T}}$, and $V$. cholerae CECT $514^{\mathrm{T}}$ were determined and compared with previously published sequences of 10 reference species of the genus Vibrio (12).

A matrix of overall similarity values for the new and the 
TABLE 3. Levels of 16S rRNA sequence similarity between Vibrio species

\begin{tabular}{|c|c|c|c|c|c|c|c|c|c|c|c|c|c|c|}
\hline \multirow[b]{2}{*}{ Taxon } & \multicolumn{14}{|c|}{$\%$ Similarity to: } \\
\hline & 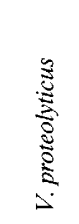 & 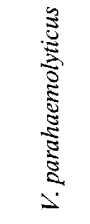 & 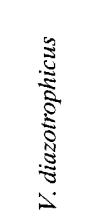 & 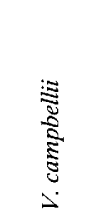 & 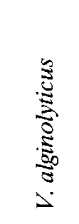 & D. & 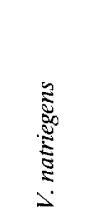 & $\begin{array}{l}\frac{3}{5} \\
\frac{3}{5} \\
\lambda\end{array}$ & $\frac{: \overrightarrow{3}}{\stackrel{5}{3}}$ & 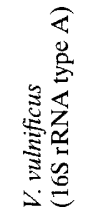 & 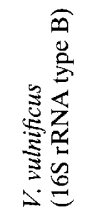 & 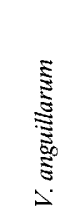 & 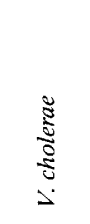 & 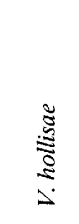 \\
\hline E. coli & 89.32 & 88.96 & 90.61 & 89.46 & 89.52 & 89.82 & 90.20 & 90.09 & 89.95 & 89.82 & 89.96 & 89.32 & 90.28 & 89.04 \\
\hline V. proteolyticus & & 97.62 & 95.12 & 97.01 & 97.14 & 97.64 & 97.84 & 95.74 & 95.49 & 95.67 & 96.15 & 95.21 & 92.85 & 93.19 \\
\hline$V$. parahaemolyticus & & & 95.20 & 96.41 & 96.47 & 97.10 & 97.43 & 96.44 & 96.13 & 96.51 & 95.83 & 94.82 & 92.47 & 93.07 \\
\hline V. diazotrophicus & & & & 95.41 & 95.54 & 95.88 & 96.08 & 96.29 & 95.04 & 96.70 & 96.77 & 96.37 & 94.29 & 93.12 \\
\hline V. campbellii & & & & & 96.60 & 98.90 & 98.55 & 96.04 & 95.66 & 95.97 & 96.45 & 95.44 & 92.83 & 93.33 \\
\hline$V$. alginolyticus & & & & & & 99.17 & 98.75 & 96.11 & 95.72 & 96.04 & 96.45 & 95.51 & 93.03 & 93.46 \\
\hline$V$. harveyi & & & & & & & 98.69 & 96.53 & 96.19 & 96.45 & 96.66 & 95.91 & 93.18 & 93.54 \\
\hline$V$. natriegens & & & & & & & & 96.86 & 96.66 & 96.72 & 97.21 & 96.04 & 93.30 & 93.80 \\
\hline$V$. fluvialis & & & & & & & & & 98.50 & 97.98 & 97.59 & 95.58 & 94.98 & 93.33 \\
\hline V. furnissii & & & & & & & & & & 96.94 & 96.55 & 94.84 & 94.00 & 93.78 \\
\hline V. vulnificus (16S rRNA type A) & & & & & & & & & & & 98.83 & 96.98 & 95.05 & 93.54 \\
\hline$V$. vulnificus (16S rRNA type B) & & & & & & & & & & & & 97.32 & 94.85 & 93.61 \\
\hline$V$. anguillarum & & & & & & & & & & & & & 94.17 & 92.47 \\
\hline$V$. cholerae & & & & & & & & & & & & & & 90.85 \\
\hline
\end{tabular}

previously published (12) vibrio sequences is shown in Table 3. The phylogenetic tree in Fig. 1 was based on the results of a maximum-likelihood analysis and was corrected by taking into account the results of distance and maximum-parsimony analyses of different data sets. In general, the topology of the tree was supported by the results of the majority of the different analyses. However, the short internode branches connecting the $V$. fuvialis- $V$. furnissii, $V$. hollisae, $V$. diazotrophicus, and $L$. anguillarum- $V$. vulnificus lines indicate that the relative branching order in this part of the tree is less significant.

In addition, partial sequences of the 23S rRNA genes of $V$. vulnificus biotype 1 strains TW1 and C7184, $V$. fluvialis NCTC $11327^{\mathrm{T}}$, V. furnissii ATCC $35016^{\mathrm{T}}$, V. cholerae CECT $514^{\mathrm{T}}$, and $V$. harveyi NCIMB $1280^{\mathrm{T}}$ were determined. The fragments sequenced were homologous to positions 0 to 650,1560 to 2040, and 2440 to 2750 of the Escherichia coli 23S rRNA (9) and included variable regions. The sequences were aligned and compared with all available bacterial 23S rRNA sequences in order to search for specific target sites.

Identification of $V$. vulnificus with rRNA-targeted oligonu-

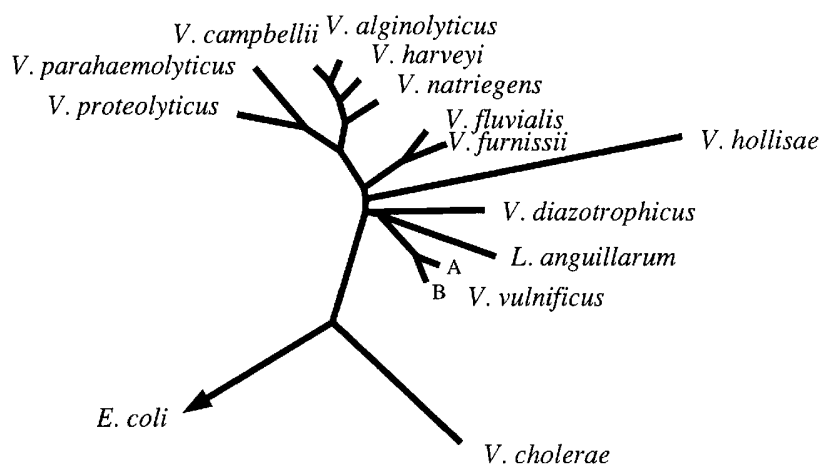

FIG. 1. Phylogenetic tree showing the phylogenetic relationships of V. vulnificus and other Vibrio species. cleotide probes. The sequences and designations of the oligonucleotide probes used and the hybridization conditions used are summarized in Table 2.

The specificity of the oligonucleotide probes was evaluated by performing dot blot hybridization experiments with membrane-bound RNAs from 21 strains of $V$. vulnificus, 13 strains belonging to other Vibrio species, 61 strains belonging to species that are members of the alpha, beta, and gamma subclasses of the Proteobacteria, and 3 eucaryotic microorganisms. The results of the dot blot hybridization experiments performed with the specific probes and with genomic DNAs from vibrios and other reference bacteria are shown in Fig. 2 and Table 4.

The oligonucleotide probes were also used in colony hybridization experiments. $V$. vulnificus strains, $V$. fluvialis NCTC $11327^{\mathrm{T}}, V$. furnissii ATCC $35016^{\mathrm{T}}$, $V$. cholerae CECT $514^{\mathrm{T}}$, and $V$. harveyi NCIMB $1280^{\mathrm{T}}$ were grown on Qiabrane membranes layered on brain heart infusion agar as described above. Hybridization experiments performed with the $V$. vulnificusspecific probes labelled with digoxigenin produced results that were the same as the results obtained with radioactively labelled probes.

In situ identification of whole cells was performed by using the tetramethylrhodamine-labelled $V$. vulnificus-specific probes. Three V. vulnificus-specific probes (Vvu1, Vvu2, Vvu3) and fluorescein-labelled universal probe EUB338 (2) were tested by performing in situ hybridization experiments. Twenty-one V. vulnificus biotype 1 and 2 strains and strains of other Vibrio species were used in in situ identification experiments. Listonella (Vibrio) anguillarum NCIMB 2129 was used as a control strain for hybridization experiments; this organism was negative for specific probes and positive for the universal probe. Mixtures containing Listonella (Vibrio) anguillarum (basonym, Listonella anguillarum) NCIMB 2129 and one of the $V$. vulnificus strains were in situ hybridized to every probe mentioned above and also simultaneously to EUB338 and every specific probe. When the fluorescein-specific filter set was used, both $V$. vulnificus and Listonella (Vibrio) anguillarum were green, but when the rhodamine-specific filter set was used, only $V$. vulnificus was red. Figure 3 and Table 4 show the results of the 


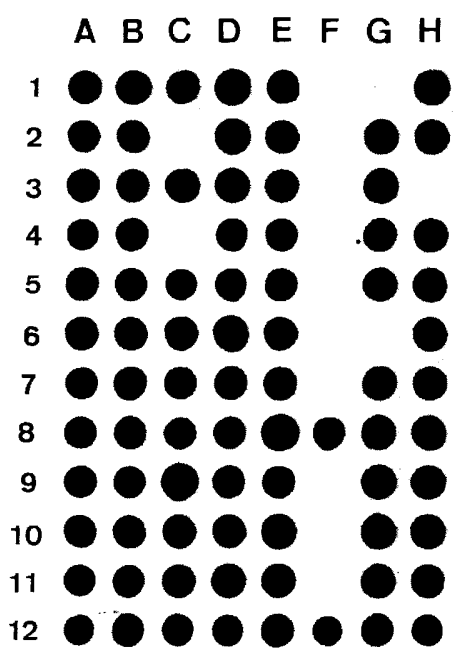

Probes: EUB338 "universal probe"
A B C D E F G H

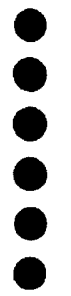

Vvu2 or Vvu3
A B C D E F G H

FIG. 2. Dot blot hybridization experiments performed with crude RNAs from members of the alpha, beta, and gamma subdivisions of the Proteobacteria and three eucaryotic microorganisms, universal probe EUB338, and probes reacting with all $V$. vulnificus strains (probes Vvu2 and Vvu3) and with some of the strains (rRNA type A; see Table 2) (probe Vvu1). RNAs from 84 organisms were immobilized on membranes and arranged as indicated in Table 1 . Positions C.2, C.4, G.1, G.6, and H.3 were empty.

color differential visualization experiments. Probes Vvu1 and Vvu2 hybridized poorly in situ and produced weak signals. In contrast, probe Vvu3 hybridized specifically to every $V$, vulnificus strain tested and produced strong hybridization signals (Fig. 3). The weak hybridization signals obtained with probes Vvu1 and Vvu2 may indicate that the target sites were not fully

TABLE 4. Probe specificities for vibrios as determined by dot blot and/or in situ hybridization experiments

\begin{tabular}{|c|c|c|c|c|}
\hline \multirow[t]{2}{*}{ Strain(s) } & \multicolumn{4}{|c|}{$\begin{array}{l}\text { Reactions with the } \\
\text { following probes: }\end{array}$} \\
\hline & Vvul & Vvu2 & Vvu3 & Vvu4 \\
\hline \multicolumn{5}{|l|}{$V$. vulnificus biotype 1 strains } \\
\hline $\begin{array}{l}\text { ATCC } 27562^{\mathrm{T}}, \mathrm{VvL} 1, \mathrm{UMH} 1 \\
63,335,647\end{array}$ & + & + & + & - \\
\hline L-180, 374, C7184, TW1, E114 & - & + & + & + \\
\hline $\begin{array}{l}\text { V. vulnificus biotype } 2 \text { strains } \\
\text { NCIMB } 2138 \text {, NCIMB } 2137 \text {, } \\
\text { NCIMB 2136, ATCC } 33149 \text {, } \\
\text { E22, E39, E58, E64, E86, and } \\
\text { E105 }\end{array}$ & + & + & + & - \\
\hline$V$. cholerae $\mathrm{O} 1$ strain CECT $514^{\mathrm{T}}$ & - & - & - & - \\
\hline$V$. cholerae non-O1 strain 137 & - & - & $\mathrm{NT}^{u}$ & - \\
\hline V. fluvialis NCTC $11327^{\mathrm{T}}$ & - & - & - & - \\
\hline V. furnissii ATCC $35016^{\mathrm{T}}$ & - & - & - & - \\
\hline V. harveyi $\mathrm{NCIMB} 1280^{\mathrm{T}}$ & - & - & - & - \\
\hline $\begin{array}{l}\text { Listonella (Vibrio) anguillarum } \\
\text { NCIMB } 2129 \text { and NCIMB } 6^{\mathrm{Tb}}\end{array}$ & - & - & - & NT \\
\hline 8 other Vibrio strains ${ }^{b}$ & - & - & - & NT \\
\hline $\begin{array}{l}61 \text { strains belonging to species } \\
\text { that are members of the alpha, } \\
\text { beta, and gamma subclasses of } \\
\text { the Proteobacteria }\end{array}$ & - & - & - & NT \\
\hline 3 eucaryotic microorganisms ${ }^{b}$ & - & - & - & NT \\
\hline
\end{tabular}

\footnotetext{
${ }^{a} \mathrm{NT}$, not tested.

$b$ The probe specificities of these microorganisms were determined by performing dot blot hybridization experiments.
}

accessible to the probes when the in situ cell hybridization technique was used. Nevertheless, these probes are excellent tools for analyzing extracted nucleic acids.

\section{DISCUSSION}

Seven different vibrio 16S rRNA gene sequences were determined. A careful comparative sequence analysis revealed that most of the Vibrio species formed a phylogenetically tight group. However, $V$. vulnificus and Listonella (Vibrio) anguillarum branched off separately from the main cluster. This finding is not in complete agreement with a phylogenetic tree inferred from a comparative analysis of $16 \mathrm{~S}$ rRNA sequences obtained by reverse transcription of cDNAs from Vibrio species (12). According to the data of Dorsch et al. (12), $V$. vulnificus is more closely related to $V$. parahaemolyticus and belongs to the main cluster of Vibrio species, whereas Listonella (Vibrio) anguillarum represents an individual subline of descent. Our results are in good agreement with the results of comparative immunological studies of superoxide dismutases of vibrios (4). According to the superoxide dismutase data, $V$. vulnificus represents a group that is not closely related to the core organisms of the genus Vibrio. Our data show that $V$. vulnificus groups together with Listonella (Vibrio) anguillarum and $V$. diazotrophicus. The closer relationship of $V$. vulnificus and $V$. parahaemolyticus reported by Dorsch et al. (12) is not supported by the extended data set. Additional taxonomic studies will be necessary to decide whether the genus Listonella should be conserved and whether $V$. vulnificus should be transferred to this genus.

$V$. furnissii was originally described as a gas-producing biogroup of $V$. fluvialis. The two species are indistinguishable by conventional serological methods. This close relationship is confirmed by the high level of 16S rRNA similarity of the two species.

A previous comparative sequence analysis of $5 \mathrm{~S}$ rRNAs of members of the family Vibrionaceae revealed a close relationship between $V$. cholerae and $V$. vulnificus $(20)$. However, this 

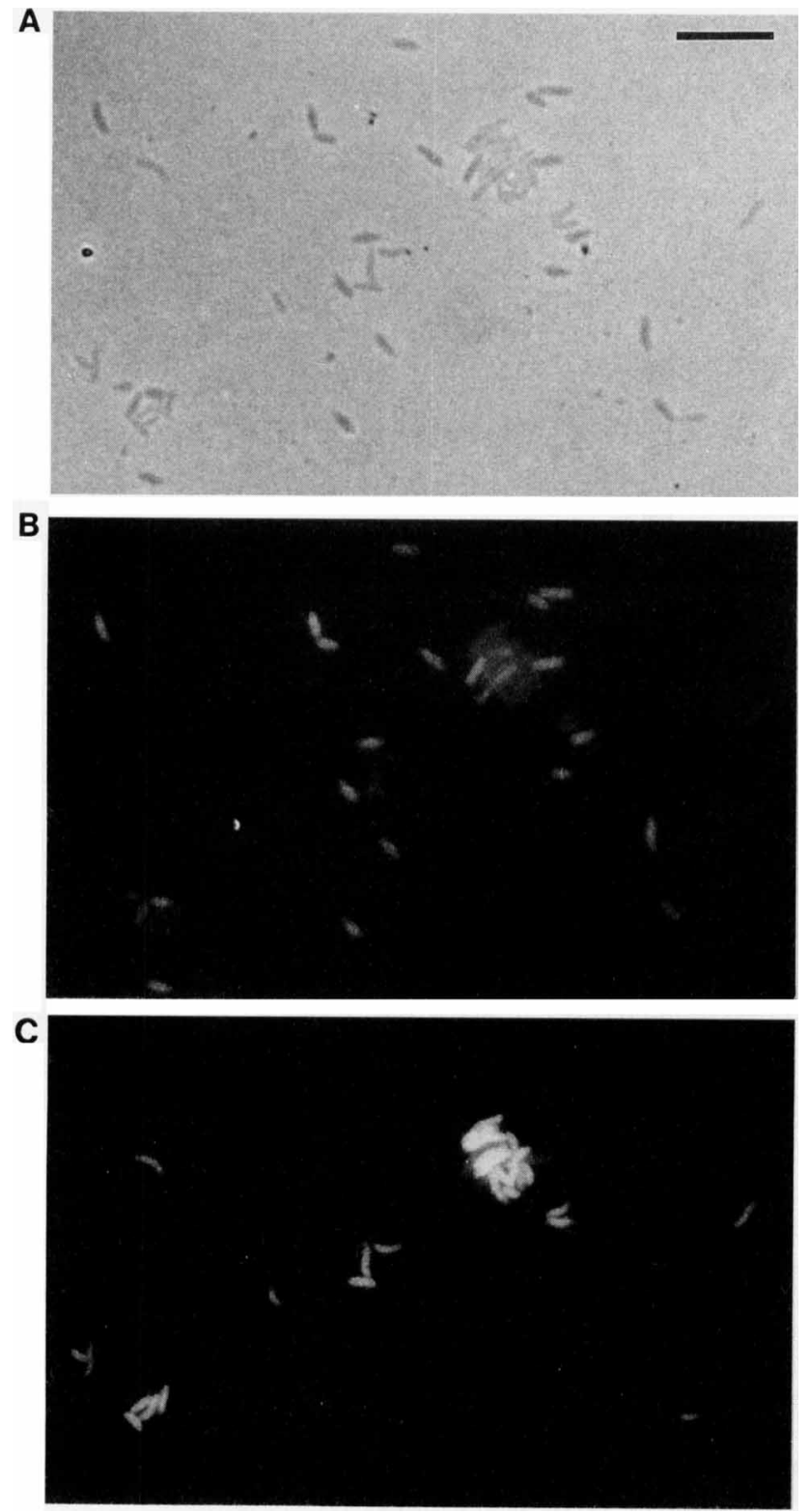

FIG, 3. Whole-cell hybridization. Cells of $V$. vulnificus ATCC $27562^{\mathrm{T}}$ and Listonella (Vibrio) anguillarum NCIMB 2129 were simultaneously hybridized with fluorescein-labelled probe Vvu3 and a tetramethylrhodamine-labelled probe specific for $L$. anguillarum (32). Identical fields were viewed by phase-contrast microscopy (A) and epifluorescence microscopy (B and C), using fluorescein-specific (B) and rhodamine-specific (C) filter sets. Bar $=10 \mu \mathrm{m}$.

finding is not consistent with the phylogenetic relationship deduced from $16 \mathrm{~S}$ rRNA data $(12,18$; this study) and from a more recent 5S rRNA analysis (10). Both the $16 \mathrm{~S}$ rRNA data and the more recent $5 \mathrm{~S}$ rRNA data show that $V$. cholerae is not closely related to $V$. vulnificus and does not belong to the core group of vibrios, but is only distantly related to this group. On the basis of these results, it has been suggested that the species $V$. cholerae should be elevated to genus rank (18).

The phylogenetic position of $V$. hollisae has to be regarded as preliminary. The remarkable length of the $V$. hollisae branch may indicate that the genes of this organism evolved more rapidly. Whereas the overall tree topology shown in Fig. 1 was stable as determined by the majority of analyses in which different treeing methods and a variety of data sets were used, the branching point of $V$. hollisae was rather unstable. In particular, distance matrix methods tend to place the $V$. hollisae branch at a lower position between $V$. cholerae and the other vibrios.

The topology of a phylogenetic tree is influenced by the composition of the underlying data set. The addition of new sequences obviously results in more phylogenetic information and in improved, often restructured phylogenetic trees. There are some significant differences between the phylogenetic tree inferred from a limited data set by Dorsch et al. (12) and our new tree (see above). Very recently, Kita-Tsukamoto et al. (18) determined the partial sequences of $16 \mathrm{~S}$ rRNAs $(600$ of about 1,500 bases) from 50 marine bacteria, mainly members of the family Vibrionaceae. The phylogenetic tree constructed from their data differed remarkably from our tree. The deep branching of $V$. cholerae is supported by the partial sequence data, but the moderately closely related species cannot be distinguished from the more closely related species. For instance, the partial sequence data are not sufficient to show the close relationship of Listonella (Vibrio) anguillarum and $V$. diazotrophicus and their separation from the core group of vibrios. This example demonstrates that the full resolution power of comparative $16 \mathrm{~S}$ rRNA analyses can be achieved only when complete or almost complete sequences are compared. Comparisons of partial sequences are not sufficient for fine resolution and may indicate wrong relationships.

The assignment of $V$. vulnificus strains to two biotypes (biotypes 1 and 2) defined by biochemical and immunological properties does not reflect the natural 1elationships of the strains. The close relationship of the type strain of the species (a biotype 1 strain) and the biotype 2 strains is corroborated by the identical $16 \mathrm{~S}$ and $23 \mathrm{~S}$ rRNA sequences of these organisms (rRNA type A), whereas the minor sequence differences $(1.1 \%)$ among biotype 1 strains indicate that there is a higher degree of heterogeneity within this biotype.

\section{ACKNOWLEDGMENTS}

R. Aznar thanks Conselleria de Cultura Educació i Ciència de la Generalitat Valenciana for her postdoctoral fellowship. This work was supported by European Community grant BIO-CT-91-0294.

\section{REFERENCES}

1. Amann, R. I., B. J. Binder, R. J. Olson, S. W. Chrisholm, R. Devereux, and D. A. Stahl. 1990. Combination of $16 \mathrm{~S}$ rRNAtargeted oligonucleotide probes with flow cytometry for analyzing mixed microbial populations. Appl. Environ. Microbiol. 56:19191925.

2. Amann, R. I., L. Krumholz, and D. A. Stahl. 1990. Fluorescent oligonucleotide probing of whole cells for determinative phylogenetic and environmental studies in microbiology. J. Bacteriol. 172:762-770.

3. Amaro, C., E. G. Biosca, B. Fouz, and E. Garay. 1992. Electrophoretic analysis of heterogeneous lipopolysaccharides from various strains of Vibrio vulnificus biotypes 1 and 2 by silver staining and immunoblotting. Curr. Microbiol. 25:99-104.

4. Baumann, L., S. S. Bang, and P. Baumann. 1980. Study of relationship among species of Vibrio, Photobacterium, and terrestrial enterobacteria by an immunological comparison of glutamine synthetase and superoxide dismutase. Curr. Microbiol. 4:133-138.

5. Baumann, P., L. Baumann, and J. L. Reichelt. 1973. Taxonomy of marine bacteria: Beneckea parahaemolytica and Beneckea alginolytica. J. Bacteriol. 113:1144-1155.

6. Betzl, D., W. Ludwig, and K. H. Schleifer. 1990. Identification of lactococci and enterococci by colony hybridization with $23 \mathrm{~S}$ 
rRNA-targeted oligonucleotide probes. Appl. Environ. Microbiol. 56:2927-2929.

7. Biosca, E. G., C. Amaro, C. Esteve, E. Alcaide, and E. Garay. 1991. First record of Vibrio vulnificus biotype 2 from diseased European eel, Anguilla anguilla L. J. Fish Dis. 14:103-109.

8. Brauns, L. A., M. C. Hudson, and J. D. Oliver. 1991. Use of the polymerase chain reaction in detection of culturable and nonculturable Vibrio vulnificus cells. Appl. Environ. Microbiol. 57:26512655.

9. Brosius, J., T. J. Dull, D. D. Sleeter, and H. F. Noller. 1981. Gene organization and primary structure of a ribosomal RNA operon from Escherichia coli. J. Mol. Biol. 148:107-127.

10. Coyne, V. E., C. J. Pillidge, D. D. Sledjeski, H. Hori, B. A. Ortiz-Conde, D. G. Muir, R. M. Weiner, and R. R. Colwell. 1989. Reclassification of Alteromonas colwelliana to the genus Shewanella by DNA-DNA hybridization, serology and 5 S ribosomal RNA sequence data. Syst. Appl. Microbiol. 12:275-279.

11. DeLong, E. F., G. S. Wickham, and N. R. Pace. 1989. Phylogenetic stains: ribosomal RNA-based probes for the identification of single cells. Science 243:1360-1363.

12. Dorsch, M., D. Lane, and E. Stackebrandt. 1992. Towards a phylogeny of the genus Vibrio based on 16S rRNA sequences. Int. J. Syst. Bacteriol. 42:58-63.

13. Farmer, J. J., III. 1980. Revival of the name Vibrio vulnificus. Int. J. Syst. Bacteriol. 30:656.

14. Felsenstein, J. 1982. Numerical methods for inferring phylogenetic trees. Q. Rev. Biol. 57:379-404.

15. Hertel, C., W. Ludwig, M. Obst, R. F. Vogel, W. P. Hammes, and K. H. Schleifer. 1991. 23S rRNA-targeted oligonucleotide probes for the rapid identification of meat lactobacilli. Syst. Appl. Microbiol. 14:173-177.

16. Hill, W. E., S. P. Keasler, M. W. Trucksess, P. Feng, C. A. Kaysner, and K. A. Lampel. 1991. Polymerase chain reaction identification of Vibrio vulnificus in artificially contaminated oysters. Appl. Environ. Microbiol. 57:707-711.

17. Jukes, T. H., and C. R. Cantor. 1969. Evolution of protein molecules, p. 21-132. In H. N. Munro (ed.), Mammalian protein metabolism. Academic Press, New York.

18. Kita-Tsukamoto, K., H. Oyaizu, K. Nanba, and U. Simidu. 1993. Phylogenetic relationships of marine bacteria, mainly members of the family Vibrionaceae, determined on the basis of 16S rRNA sequences. Int. J. Syst. Bacteriol. 43:8-19.

19. Ludwig, W., G. Kirchhof, N. Klugbauer, M. Weizenegger, D. Betzl, M. Ehrmann, C. Hertel, S. Jilig, R. Tatzel, H. Zitzelsberger, S. Liebl, M. Hochberger, D. Lane, P. R. Wallnöfer, and K. H.
Schleifer. 1993. Complete 23S ribosomal RNA sequences of gram-positive bacteria with a low DNA G+C content. Syst. Appl. Microbiol. 15:487-501.

20. MacDonell, M. T., and R. R. Colwell. 1985. Phylogeny of Vibrionaceae and recommendation for two new genera, Listonella and Shewanella. Syst. Appl. Microbiol. 6:171-182.

21. Morris, J. G., Jr., A. C. Wright, D. R. Roberts, P. K. Wood, L. M. Simpson, and J. D. Oliver. 1987. Identification of environmental Vibrio vulnificus isolates with a DNA probe for the cytotoxinhemolysin gene. Appl. Environ. Microbiol. 53:193-195.

22. Olsen, G. J., R. Overbeek, N. Larsen, T. L. Marsh, M. J. McCaughey, M. A. Maciukenas, W. M. Kuan, T. J. Macke, Y. Xing, and C. R. Woese. 1992. The ribosomal database project. Nucleic Acids Res. 20(Suppl.):2199-2200.

23. O'Neil, K. R., S. H. Jones, and D. J. Grimes. 1992. Seasonal incidence of Vibrio vulnificus in the Great Bay Estuary of New Hampshire and Maine. Appl. Environ. Microbiol. 58:3257-3262.

24. Pitcher, D. G., N. A. Saunders, and R. J. Owen. 1989. Rapid extraction of bacterial genomic DNA with guanidium thiocyanate. Lett. Appl. Microbiol. 8:151-156.

25. Reichelt, J. L., P. Baumann, and L. Baumann. 1976. Study of genetic relationships among marine species of the genera $B e$ neckea and Photobacterium by means of in vitro DNA/DNA hybridization. Arch. Microbiol. 110:101-120.

26. Saitou, N., and M. Nei. 1987. The neighbor-joining method: a new method for reconstructing phylogenetic trees. Mol. Biol. Evol. 4:406-425.

27. Sambrook, J., E. F. Fritsch, and T. Maniatis. 1989. Molecular cloning: a laboratory manual, 2nd ed. Cold Spring Harbor Laboratory, Cold Spring Harbor, N.Y.

28. Schleifer, K. H., W. Ludwig, and R. Amann. 1993. Nucleic acid probes, p. 463-509. In M. Goodfellow and A. O. O'Donnell (ed.), Handbook of new bacterial systematics. Academic Press, London.

29. Stelma, G. N., Jr., A. L. Reyes, J. T. Peeler, C. H. Johnson, and P. L. Spaulding. 1992. Virulence characteristics of clinical and environmental isolates of Vibrio vulnificus. Appl. Environ. Microbiol. 58:2776-2782.

30. Tison, D. L., M. Nishibuchi, J. D. Greenwood, and R. J. Seidler. 1982. Vibrio vulnificus biogroup 2: new biogroup pathogenic for eels. Appl. Environ. Microbiol. 44:640-646.

31. Tison, D. L., and R. J. Seidler. 1981. Genetic relatedness of clinical and environmental isolates of lactose-positive Vibrio vulnificus. Curr. Microbiol. 6:181-184.

32. Westerdahl, A., and R. I. Amann. Unpublished data. 